02

\title{
Структурная анизотропия пленок аморфного кремния, модифицированных фемтосекундными лазерными импульсами*
}

\author{
() Д.В. Шулейко ${ }^{1}$, Ф.В. Кашаев ${ }^{1}$, Ф.В. Потемкин ${ }^{1}$, С.В. Заботнов ${ }^{1,2,3}$, А.В. Зотеев ${ }^{1}$, \\ Д.Е. Преснов ${ }^{1,4}$, И.Н. Пархоменко ${ }^{5}$, И.А. Романов ${ }^{5}$ \\ ${ }^{1}$ Московский государственный университет им. М.В. Ломоносова, фризический фракультет, \\ 119991 Москва, Россия \\ ${ }^{2}$ Национальный исследовательский центр „Курчатовский институт“, \\ 123182 Москва, Россия \\ ${ }^{3}$ Московский физико-технический институт, ИНБИКСТ, \\ 123098, Москва, Россия \\ ${ }^{4}$ Московский государственный университет им. М.В. Ломоносова, \\ Научно-исследовательский институт ядерной физики им. Д.В. Скобельцына, \\ 119991 Москва, Россия \\ ${ }^{5}$ Белорусский государственный университет, \\ 220030 Минск, Республика Беларусь \\ e-mail: shuleyko.dmitriy@physics.msu.ru
}

Поступила в редакцию 06.02.2018 г.

Показано, что ориентация поверхностного рельефа в виде одномерных решеток с периодом $1.20 \pm 0.02 \mu \mathrm{m}$, формируемого при обработке пленок аморфного гидрогенизированного кремния фемтосекундными лазерными импульсами $(1.25 \mu \mathrm{m})$ с плотностью энергии $0.15 \mathrm{~J} / \mathrm{cm}^{2}$, определяется направлением вектора поляризации использованного излучения и совокупной дозой экспозиции. В облученных областях пленок зарегистрировано присутствие нанокристаллической фазы кремния, объемная доля которой (в зависимости от условий обработки) составляет от 15 до $67 \%$ согласно результатам анализа спектров комбинационного рассеяния света. Наблюдаемые процессы микро- и наноструктурирования обусловлены соответственно возбуждением поверхностных плазмон-поляритонов и нанокристаллизацией в приповерхностной области в поле мощных фемтосекундных лазерных импульсов. Кроме того, обнаружено формирование полиморфных модификаций кремния Si-III и Si-XII при фемтосекундной лазерной обработке с числом импульсов излучения более 500, а также зарегистрирована анизотропия сигнала комбинационного рассеяния света для данных полиморфных модификаций.

DOI: $10.21883 /$ OS.2018.06.46079.38-18

\section{Введение}

Аморфный гидрогенизированный кремний $(a-\mathrm{Si}: \mathrm{H})$, модифицированный фемтосекундными лазерными импульсами, представляет интерес для тонкопленочной солнечной энергетики [1]. Обработка пленок $a-\mathrm{Si}: \mathrm{H}$ сверхкороткими лазерными импульсами позволяет получить однородно распределенные по объему пленки нанокристаллы кремния [2-4], что приводит к росту проводимости, а также уменьшает наблюдаемый в таких системах эффект Стеблера-Вронского [5]. Кроме того, при фемтосекундной лазерной обработке пленок $a$-Si:H происходит структурирование их поверхности, что позволяет повысить эффективность солнечных элементов на основе данного материала за счет увеличения поглощающей способности $[6,7]$. При этом может также наблюдаться анизотропия структурных, оптических и электрофизических свойств облученной поверхности $[1,8-10]$. В частности, под действием мощных сверхкоротких лазерных импульсов на пленках $a-\mathrm{Si}: \mathrm{H}$ могут быть сформированы поверхностные периодиче-

\footnotetext{
* Х Международная конференция молодых ученых и специалистов „Оптика 2017“, 16-20 октября 2017 г., Санкт-Петербург, Россия
}

ские структуры (ППС) [11] за счет эффективной генерации электрон-дырочной плазмы в полупроводнике с последующим возбуждением плазмон-поляритонов [12]. Такие пленки $a$-Si:H могут быть использованы для создания двулучепреломляющих элементов оптики, когда при обработке возникают ППС, в которых проявляется анизотропия формы в виде периодической модуляции комплексного показателя преломления обработанного материала [13]. При этом, как показано в работе [11], вид и ориентация поверхностного рельефа могут контролироваться за счет изменения режима фемтосекундной лазерной обработки, что позволяет формировать элементы фотоники субмикронного размера и заданной ориентации на поверхности пленки $a-\mathrm{Si}: \mathrm{H}$.

Тем не менее к настоящему времени не проводилось комплексных исследований влияния режима фемтосекундного лазерного структурирования на такие параметры пленок $a$ - $\mathrm{Si}: \mathrm{H}$, как вид получаемых на поверхности микроструктур, соотношение аморфной и кристаллической фаз и наличие полиморфных модификаций кремния. В частности, не исследовано влияние общей дозы экспозиции лазерного излучения при постоянной энергии 
в импульсе на вышеуказанные параметры. Поэтому в настоящей работе поставлена цель проведения и анализа экспериментов, устанавливающих и описывающих взаимосвязь данных параметров пленок $a-\mathrm{Si}: \mathrm{H}$, модифицированных фемтосекундными лазерными импульсами, в зависимости от изменения совокупной дозы излучения. Кроме того, в настоящей работе впервые исследована анизотропия сигнала комбинационного рассеяния света (КРС) модифицированных пленок $a$-Si: H, которая представляет интерес как инструмент неразрушающего анализа структуры таких объектов.

\section{Экспериментальные методики}

Исследуемые пленки $a$-Si:H толщиной $600 \mathrm{~nm}$, полученные методом плазмохимического осаждения из газовой фазы на стеклянных подложках [2,11], были облучены фемтосекундными лазерными импульсами. В качестве источника излучения была использована лазерная система „Авеста“ на основе кристалла хром-форстерита (длина волны излучения - $1250 \mathrm{~nm}$, длительность, энергия и частота следования импульсов $-125 \mathrm{fs}, 130 \mu \mathrm{J}$ и $10 \mathrm{~Hz}$ соответственно). Диаметр лазерного пятна составлял $300 \mu \mathrm{m}$, чтобы обеспечить плотность энергии $0.15 \mathrm{~J} / \mathrm{cm}^{2}$ в одиночном импульсе. Обработка пленок $a$-Si:H фемтосекундными лазерными импульсами производилась в сканирующем режиме, который осуществлялся путем перемещения образца в горизонтальной плоскости перпендикулярно лазерному лучу с помощью системы из двух автоматизированных механических трансляторов „Standa“, управляемых с помощью персонального компьютера.

В ходе эксперимента была изготовлена серия из 6 образцов, представлявших собой одиночные полосы сканирования на поверхности пленки $a-\mathrm{Si}: \mathrm{H}$, полученные путем смещения лазерного пятна по одной из координат на расстояние $0.5 \mathrm{~mm}$ со скоростью от 3 до $120 \mu \mathrm{m} / \mathrm{s}$ (табл. 1). При этом для каждого образца было проведено сканирование как в направлении, совпадающем с ориентацией вектора поляризации лазерного излучения, так и перпендикулярно ему, чтобы определить влияние направления сканирования на наблюдаемые свойства модифицированных пленок.

За счет изменения скорости сканирования варьировалась степень наложения облученных областей от двух последовательных импульсов, что определяло общее число перекрытий $N_{s}$ в пределах диаметра сфокусированного пятна лазерного излучения. Величина $N_{s}$ определяет количество импульсов лазерного излучения, прошедших за время смещения пучка на расстояние, равное диаметру пятна:

$$
N_{s}=v D / V
$$

где $v$ - частота следования импульсов, $D$ - размер пятна лазерного излучения, $V$ - скорость сканирования. Таким образом, в ходе эксперимента изменение скорости перемещения пучка позволяло менять число перекрытий $N_{s}$ пятен лазерного излучения в диапазоне от 25 до 1000 (табл. 1).

Изображения модифицированной поверхности пленок $a-\mathrm{Si}: \mathrm{H}$ были получены методом растровой электронной микроскопии (РЭМ) с помощью микроскопа „Carl Zeiss Supra $40^{6 .}$.

Определение структурных изменений обработанных лазерным излучением пленок $a-\mathrm{Si}: \mathrm{H}$ проводилось методом спектроскопии КРС с использованием рамановского микроскопа „Horiba Jobin Yvon HR800“. Длина волны возбуждающего излучения составляла $633 \mathrm{~nm}$. Измерение спектров КРС производилось при нормальном падении в геометрии обратного рассеяния. При измерении поляризационных зависимостей спектров КРС для изменения ориентации вектора поляризации возбуждающего излучения использовалась полуволновая пластина. При определении соотношения между компонентами тензора КРС вместе с полуволновой пластиной использовался анализатор, представлявший собой поляроид. Все измерения спектров КРС проводились при комнатной температуре.

\section{Экспериментальные результаты и их обсуждение}

На обработанной поверхности $a-\mathrm{Si}: \mathrm{H}$ методом РЭМ были обнаружены различные микроструктуры, в том числе периодические (рис. 1). Вид структур зависел от совокупной дозы облучения, которая задавалась числом перекрывающихся при сканирующей обработке пятен от импульсов лазерного излучения $N_{s}$ (согласно формуле (1)).

В результате анализа полученных РЭМ-изображений было обнаружено, что при числе перекрывающихся импульсов $N_{s}$ от 25 до 100 происходит формирование поверхностных периодических структур (ППС), ориентированных перпендикулярно вектору поляризации и имеющих период $1.20 \pm 0.02 \mu \mathrm{m}$ (рис. $1, a-c$ ), что близко к длине волны использованного при обработке излучения и значительно меньше диаметра лазерного пятна. При скорости сканирования менее $30 \mu \mathrm{m} / \mathrm{s}$ и

Таблица 1. Параметры скорости сканирования и числа перекрытий пятен от импульсов лазерного излучения при фемтосекундной лазерной модификации пленки $a-\mathrm{Si}: \mathrm{H}$

\begin{tabular}{c|c|c}
\hline Образец & $\begin{array}{c}\text { Скорость } \\
\text { сканирования, } \\
\mu \mathrm{m} / \mathrm{s}\end{array}$ & $\begin{array}{c}\text { Число } \\
\text { перекрытий } \\
\text { импульсов }\end{array}$ \\
\hline 1 & 120 & 25 \\
2 & 60 & 50 \\
3 & 30 & 100 \\
4 & 15 & 200 \\
5 & 6 & 500 \\
6 & 3 & 1000
\end{tabular}



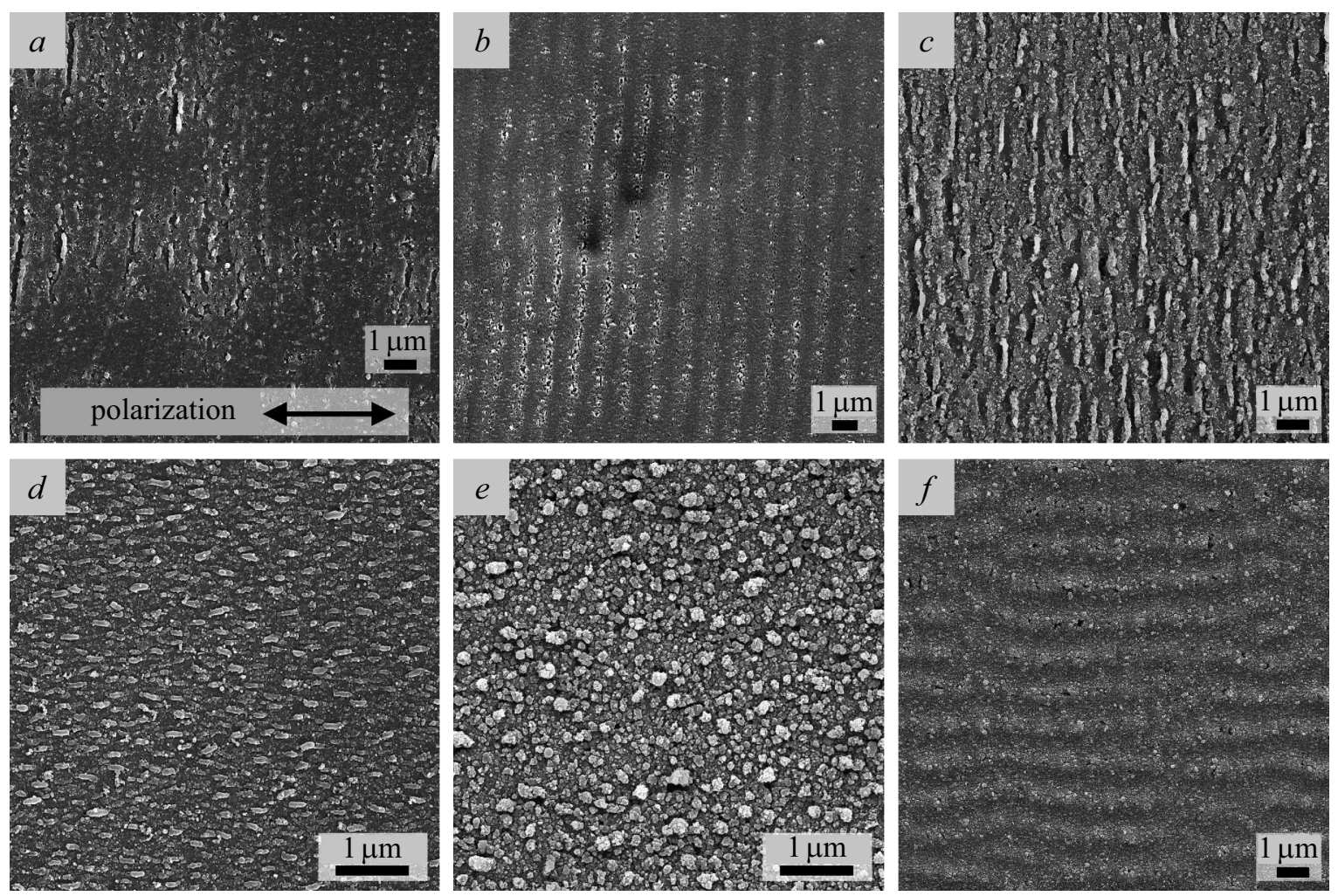

Рис. 1. Изображения поверхности пленки $a$-Si: H, обработанной фемтосекундными лазерными импульсами с плотностью потока энергии $0.14 \mathrm{~J} / \mathrm{cm}^{2}$ и числом перекрытий лазерных импульсов $25(a), 70(b), 100(c), 200(d), 500(e)$ и $1000(f)$, полученные методом РЭМ. Ориентация вектора поляризации структурирующего излучения одинакова на всех изображениях.

соответственно $N_{s}$ более 100 вместо данных решеток формируются кластерные образования длиной $\sim 400$ и шириной $\sim 100 \mathrm{~nm}$, ориентированные вдоль вектора поляризации лазерного излучения (рис. $1, d)$. При увеличении $N_{s}$ до 500 на модифицированной поверхности формируются изотропные кластеры со средним размером $\sim 200 \mathrm{~nm}$ (рис. $1, e$ ). Когда значение $N_{s}$ достигает 1000, снова наблюдается формирование одномерных решеток с тем же, что при малом числе перекрытий, периодом, но при этом имеющих ориентацию вдоль вектора поляризации лазерного излучения (рис. $1, f$ ). Также обнаружено, что ориентация всех типов структур определяется только направлением вектора поляризации использованного лазерного излучения и не зависит от того, в каком направлении производится сканирование пленки пучком.

Важно отметить, что во всех случаях обработка пленок происходила при воздействии лазерными импульсами на поверхность с плотностью энергии $0.15 \mathrm{~J} / \mathrm{cm}^{2}$, превышающей порог абляции, который, согласно работам $[14,15]$, составляет не более $0.09 \mathrm{~J} / \mathrm{cm}^{2}$ для пленок $a-\mathrm{Si}: \mathrm{H}$. В данном режиме обработки формирование ППС на поверхности полупроводника, вероятнее всего, происходит из-за генерации электрондырочной плазмы в пленке вследствие интенсивного фотовозбуждения фемтосекундными лазерными импуль- сами. Во время этого процесса поверхность пленки переходит в металлоподобное состояние, и создаются условия для возбуждения поверхностных плазмонполяритонов $[12,16]$. Интерференция падающего излучения и плазмон-поляритона приводит к периодической модуляции интенсивности поглощения и, следовательно, модулированной абляции облученной поверхности. Ориентация ППС в данном случае зависит от знака диэлектрической проницаемости $\varepsilon$ в приповерхностной области, который определяет либо ТЕ-, либо ТМ-тип возбуждаемого фемтосекундным лазерным импульсом плазмон-поляритона $[12,16]$ и, следовательно, направление распространения последнего.

Иными словами, наблюдаемое в эксперименте изменение формы получаемых поверхностных структур при увеличении совокупной дозы облучения связано с возникновением обратной связи [17] между сформированным поверхностным микрорельефом и электронными процессами, происходящими в пленке $a-\mathrm{Si}: \mathrm{H}$ при фемтосекундной лазерной обработке. Данная обратная связь может быть описана следующим образом. Образование поверхностного рельефа под действием фемтосекундных лазерных импульсов приводит к увеличению поглощения пленки $[6,7]$, поэтому каждый последующий импульс лазерного излучения вызывает более сильный нагрев пленки $a-\mathrm{Si}: \mathrm{H}$ и увеличивает тепловую эмиссию 
электронов с поверхности полупроводника. В результате в приповерхностной области знак диэлектрической проницаемости изменяется с положительного на отрицательный, что приводит к изменению моды возбуждаемых плазмон-поляритонов (ТЕ вместо ТМ), и, как следствие, ориентация формируемых ППС также изменяется $[12,16,18]$.

Следует отметить, что подобное изменение ориентации ППС при увеличении совокупной дозы облучения фемтосекундными лазерными импульсами наблюдалось также на поверхности кристаллического кремния [16,19], однако период решеток, направленных вдоль вектора поляризации, был примерно в 3 раза больше длины волны используемого лазерного излучения и периода решеток, ориентированных перпендикулярно вектору поляризации.

Случай обработки поверхности пленок $a-\mathrm{Si}: \mathrm{H}$ фемтосекундными лазерными импульсами ранее анализировался в работах $[1,11]$, но полученные структуры имели период в 3-10 раз меньше длины волны используемого излучения, и механизмы их формирования не обсуждались.

Таким образом, ППС на поверхности аморфного кремния, полученные при фемтосекундной лазерной модификации и ориентированные как параллельно, так и перпендикулярно вектору поляризации используемого излучения, с периодом, приблизительно равным длине волны, в настоящем исследовании, насколько нам известно, обнаружены впервые.

Исследования спектров КРС облученных пленок $a-\mathrm{Si}: \mathrm{H}$ показали, что во всех случаях происходила нанокристаллизация пленок: во всех спектрах наблюдается не только широкая линия, соответствующая аморфному кремнию $\omega_{A}=480 \mathrm{~cm}^{-1}$, но и узкая линия, соответствующая кристаллическому (нанокристаллическому) кремнию, вблизи $\omega_{C}=520 \mathrm{~cm}^{-1}$ (рис. 2). Кроме того, в спектрах образцов 4, 5 и 6 наблюдался сдвиг положения линии, соответствующей кристаллическому кремнию, в область меньших частот, вплоть до величины $\sim 517 \mathrm{~cm}^{-1}$.

Для оценки объемной доли кристаллической фазы $f_{C}$ были вычислены интегральные интенсивности $I_{A}$ и $I_{C}$ фононных ТО-мод, соответствующих линиям вблизи частот $\omega_{A}$ и $\omega_{C}$, а также интегральная интенсивность так называемой „промежуточной“ линии $I_{I}$, соответствующей частоте $\omega_{I}$ около $510 \mathrm{~cm}^{-1}$ (рис. 2). Интерпретация последней связана с наличием кремниевых кластеров размерами менее $10 \mathrm{~nm}$ [20] или с возникновением промежуточной фазы на границе раздела аморфного и кристаллического веществ [21].

Значение $f_{C}$ определяется с помощью следующего выражения [22,23]:

$$
f_{C}=\frac{I_{C}+I_{I}}{\sigma_{0} I_{A}+I_{C}+I_{I}},
$$

где $\sigma_{0}=0.1+\exp \left(-d_{n c-\mathrm{Si}} / 25\right)-$ эмпирическое соотношение для отношения интегральных сечений комбинационного рассеяния света в кристаллической и аморфной

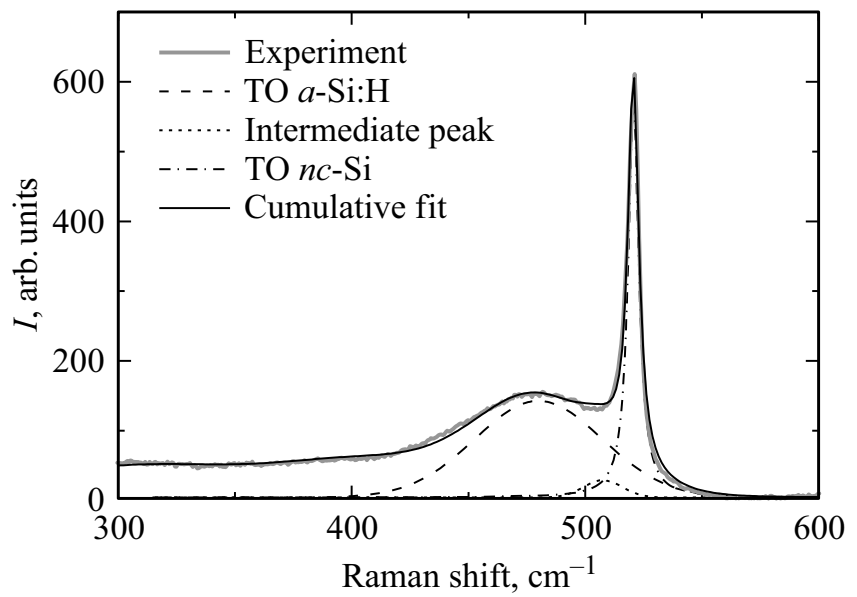

Pис. 2. Типичный спектр КРС облученной пленки $a$-Si:H (образец 3), а также его аппроксимация.

фазах кремния [24], а $d_{n c-S i}-$ средний диаметр нанокристаллов кремния в нанометрах. Наблюдаемый в спектрах образцов 4, 5 и 6 сдвиг линии КРС, соответствующей кристаллическому кремнию, позволил оценить величину $d_{n c-\mathrm{Si}}$ в данных образцах с помощью выражения $[25,26]$

$$
d_{n c-\mathrm{Si}}=a_{0}\left(\frac{A}{\omega_{C}-\omega\left(d_{n c-\mathrm{Si}}\right)}\right)^{1 / \gamma},
$$

где $a_{0}=0.543 \mathrm{~nm}$ - постоянная решетки кристаллического кремния, $\omega\left(d_{n c-\mathrm{Si}}\right)$ - частота фононной ТО-моды в нанокристалле кремния размером $d_{n c-\mathrm{Si}}, A=47.41 \mathrm{~cm}^{-1}$ и $\gamma=1.44$ - параметры размерного квантования для фононов в кремниевых нанокристаллах сферической формы [25]. Рассчитанные по формуле (3) значения $d_{n c-\mathrm{Si}}$ для образцов 4,5 и 6 представлены в табл. 2. В случае образцов 1, 2 и 3, когда сдвиг соответствующей линии КРС не был зарегистрирован, размер нанокристаллов кремния брался равным $10 \mathrm{~nm}$ согласно данным РЭМ.

Отметим, что в спектрах КРС ширина линии кристаллического кремния $\omega_{C}=520 \mathrm{~cm}^{-1}$ составляет $\sim 8 \mathrm{~cm}^{-1}$ для образцов 1, 2 и 3, а в случае образцов 4, 5 и 6 ширина данной линии оказывается равной $\sim 5 \mathrm{~cm}^{-1}$. Это позволяет оценить размер кремниевых нанокристаллов по уширению линии КРС $\omega_{C}=520 \mathrm{~cm}^{-1}$ за счет пространственного ограничения оптических фононов в нанокристаллах [27]. Полученные значения согласуются с данными, представленными в табл. 2 .

Значения объемной доли нанокристаллической фазы кремния (без учета полиморфных модификаций), рассчитанные по формуле (2), также представлены в табл. 2. Как видно из данной таблицы, для образцов 4, 5 и 6, т.е. при значениях $N_{s}$, начиная с 200 и более (табл. 1), происходит существенное уменьшение размера кремниевых нанокристаллов, а также объемной доли нанокристаллической фазы в пленке. Это можно объяснить повторной аморфизацией сформированных кремниевых 


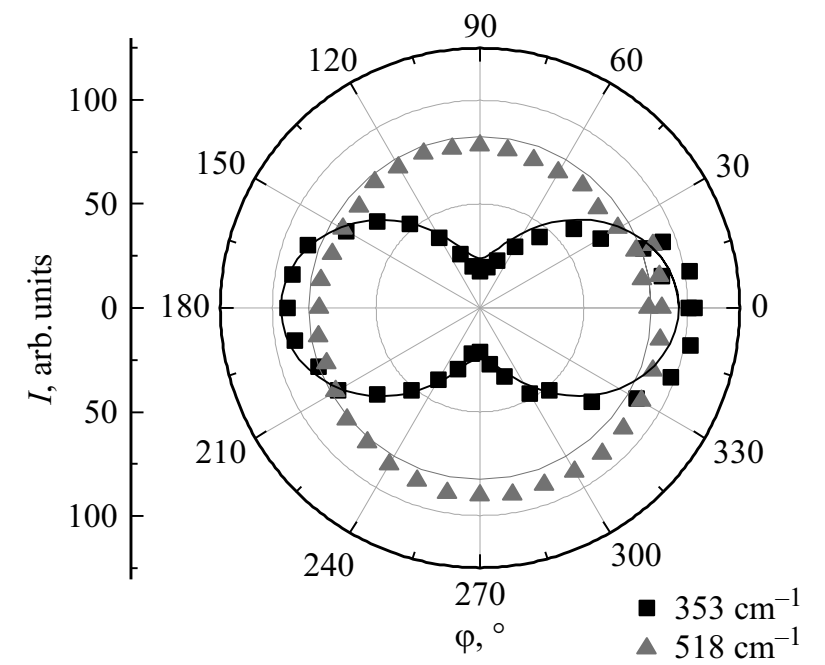

Рис. 3. Поляризационная зависимость интенсивности линий КРС, соответствующих монокристаллическому кремнию и полиморфной модификации Si-III, сплошные линии - аппроксимация. Угол $\varphi$ соответствует повороту вектора поляризации возбуждающего излучения относительно ориентации ППС.

нанокристаллов при длительной обработке пленки фемтосекундным лазерным излучением. Аналогичный процесс наблюдался в работе [28], когда при фемтосекундной модификации поверхности монокристаллического кремния происходила его аморфизация.

Кроме линий аморфного и кристаллического кремния, в спектре КРС образца 6, обработанного при числе перекрытий импульсов $N_{s}=1000$, наблюдается группа линий с положениями $160,353,386,390$ и $440 \mathrm{~cm}^{-1}$ (рис. 3), которые соответствуют полиморфным модификациям кремния Si-XII (ромбоэдрическая) и $\mathrm{Si}-\mathrm{III}$ (кубическая объемно-центрированная). Полиморфная модификация Si-XII характеризуется линиями КРС 166, 182, 352, 396, 440 и $491 \mathrm{~cm}^{-1}$, а Si-III - линиями 166 и $385 \mathrm{~cm}^{-1}$ соответственно [29]. Образование данных полиморфных модификаций кремния происходит, как правило, при высоком давлении [29]. Необходимые условия могут быть достигнуты в процессе облучения кристалли-

Таблица 2. Объемная доля нанокристаллической фазы кремния и размер кремниевых нанокристаллов, формирующихся в пленке $a-\mathrm{Si}: \mathrm{H}$ в результате фемтосекундной лазерной модификации

\begin{tabular}{c|c|c}
\hline Образец & $\begin{array}{c}\text { Размер } \\
\text { нанокристаллов, } \\
\mathrm{nm}\end{array}$ & $\begin{array}{c}\text { Объемная доля } \\
\text { нанокристаллической } \\
\text { фазы, \% }\end{array}$ \\
\hline 1 & & 31 \\
2 & 10 & 67 \\
3 & & 45 \\
4 & 4 & 17 \\
5 & 3 & 14 \\
6 & 3 & 18
\end{tabular}

ческого кремния фемтосекундными лазерными импульсами, как показано в работах [30-34]. Высокое давление может возникать во время обработки из-за реактивной отдачи аблированного материала при воздействии мощных фемтосекундных лазерных импульсов [30,33], а также после окончания действия лазерного излучения за счет механических напряжений, возникающих при повторном затвердевании расплава [34].

При исследовании поляризационной зависимости спектров КРС образца 6 обнаружено также, что интенсивность линий, соответствующих полиморфным модификациям кремния, зависит от поляризации используемого в измерениях КРС возбуждения. Наибольшая интенсивность линии КРС $353 \mathrm{~cm}^{-1}$ наблюдается, если направление вектора поляризации возбуждающего излучения и ориентация ППС, сформированных на поверхности образца 6 , совпадают. Важно отметить, что в данном случае ориентация ППС также совпадает с направлением вектора поляризации фемтосекундных лазерных импульсов, использованных при обработке. При ориентации вектора поляризации возбуждающего излучения в перпендикулярном направлении интенсивность данной линии спадает в $\sim 5$ раз (рис. 3 ). При этом также видно, что интенсивность линии КРС $\omega_{C}=518 \mathrm{~cm}^{-1}$, соответствующей кристаллическому кремнию точечной группы симметрии $m 3 m$, практически не зависит от угла поворота поляризации возбуждающего излучения.

Измерение интенсивности линии КРС вблизи частоты $353 \mathrm{~cm}^{-1}$ для образца 6 при различных ориентациях вектора поляризации возбуждающего и анализируемого излучения (рис. $4, a, b)$ позволило определить соотношения между компонентами тензора КРС данной линии. При данных измерениях ориентация векторов поляризации возбуждения и анализируемого сигнала была либо параллельна ППС, либо перпендикулярна данным структурам.

Согласно [35], интенсивность рассеянного излучения

$$
I_{s} \sim\left|e_{i} R e_{s}\right|^{2},
$$

где $e_{i}$ - поляризация падающего света, $e_{s}$ - поляризация рассеянного света, $R$ - тензор КРС. Соотношение квадратов компонент тензора КРС, соответствующих ориентации векторов поляризации излучения вдоль осей в плоскости образца $(x, y)$, было получено с использованием выражения (4) и экспериментально измеренных интенсивностей линии КРС $353 \mathrm{~cm}^{-1}$ :

$$
R_{x x}^{2} \approx d, \quad R_{y y}^{2} \approx 0, \quad R_{x y}^{2} \approx R_{y x}^{2} \approx d / 3
$$

При этом учитывалось, что в силу геометрии эксперимента при каждом из четырех измерений спектра КРС (рис. 4) ненулевой оставалась только одна компонента каждого из векторов $e_{i}$ и $e_{s}$. Соотношения (5) были использованы для аппроксимации поляризационной зависимости линии КРС вблизи частоты $353 \mathrm{~cm}^{-1}$. Результат аппроксимации представлен на рис. 3. Стоит отметить, что полученные соотношения между квадратами 
компонент тензора КРС для линии, соответствующей полиморфной модификации $\mathrm{Si}-\mathrm{XII}$ с ромбоэдрической кристаллической решеткой, согласуются с теоретическими представлениями [36].

Зависимость интенсивности линии КРС от направления поляризации возбуждающего излучения в проведенных нами экспериментах наблюдалась только для линий, соответствующих полиморфным модификациям кремния, но не для линии КРС монокристаллического кремния вблизи $520 \mathrm{~cm}^{-1}$. Это может быть связано с тем, что оси кристаллических решеток в нанокристаллах полиморфных модификаций кремния ориентированы преимущественно в одном направлении относительно вектора поляризации используемого при обработке лазерного излучения с линейной поляризацией $[34,37,38]$. Подобная ориентация нанокристаллов, вероятнее всего, происходит в процессе их формирования из-за наличия
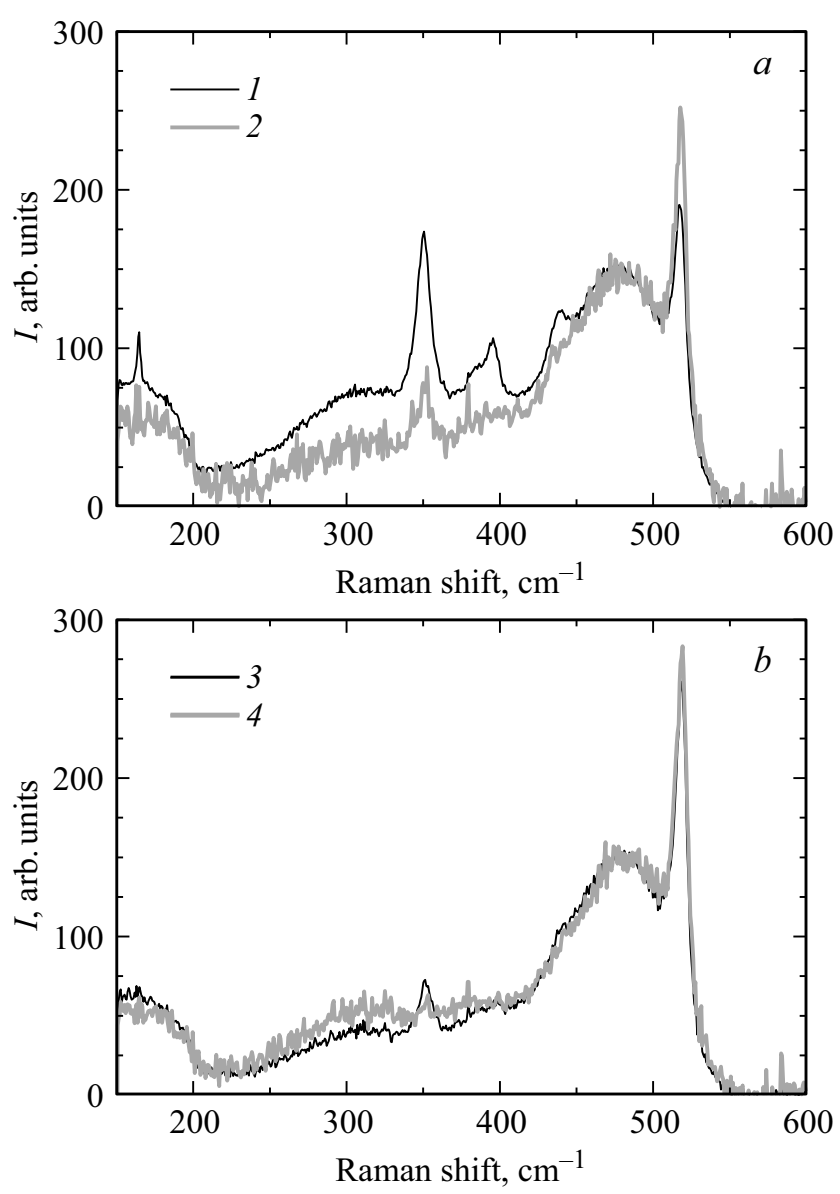

Рис. 4. Спектры КРС образца 6, полученные при различной ориентации вектора поляризации возбуждающего и анализируемого излучения относительно сформированных ППС. Цифрами обозначены спектры КРС в случае, когда: 1 - оба вектора поляризации параллельны ППС; 2 - поляризация возбуждающего излучения параллельна ППС, а анализируемого - перпендикулярна $(a) ; 3$ - поляризация возбуждающего излучения перпендикулярна ППС, а анализируемого параллельна; 4 - оба вектора поляризации перпендикулярны ППС $(b)$. температурных градиентов и модулированного нагрева пленки [37], происходящего при фемтосекундной лазерной обработке в результате интерференции падающего излучения и поверхностных плазмон-поляритонов.

\section{Заключение}

Таким образом, в представленной работе было показано, что ориентация ППС с характерным периодом $1.20 \pm 0.02 \mu \mathrm{m}$, сформированных на поверхности пленки $a$-Si:H фемтосекундным лазерным излучением, зависит от совокупной дозы экспозиции. Наблюдаемый эффект вызван наличием обратной связи между формируемым поверхностным рельефом и электронными процессами в пленке: за счет формирования ППС увеличивается поглощающая способность пленки и происходит более сильный ее нагрев, сопровождающийся более интенсивной эмиссией электронов с поверхности полупроводника. Это приводит к изменению знака диэлектрической проницаемости в приповерхностном слое. В результате происходит изменение возбуждаемой моды плазмонполяритонов (ТЕ вместо ТМ) и соответственно ориентации формируемых ППС.

Определена зависимость объемной доли кристаллической фазы в пленке $a-\mathrm{Si}: \mathrm{H}$, образующейся при фемтосекундной лазерной обработке, от совокупной дозы экспозиции в случае, когда энергия одиночного импульса остается неизменной. При этом обнаружено, что при высокой совокупной дозе облучения в пленке $a-\mathrm{Si}: \mathrm{H}$ образуются полиморфные модификации кристаллического кремния (Si-III и $\mathrm{Si}-\mathrm{XII})$. При этом интенсивность линий КРС, соответствующих данным полиморфным модификациям, в случае ориентации вектора поляризации возбуждающего излучения параллельно ППС, оказывается в $~ 5$ раз выше по сравнению со случаем, когда вектор поляризации ортогонален ППС. Данная анизотропия сигнала КРС, вероятно, связана с упорядоченной ориентацией кристаллографических осей нанокристаллов полиморфных модификаций кремния, образующихся в пленке в результате импульсной лазерной модификации.

Авторы благодарят А.Г. Казанского за предоставленные образцы $a-\mathrm{Si}: \mathrm{H}$ и Л.А. Голованя за плодотворные обсуждения. Модификация пленок $a$-Si:H фемтосекундным лазерным излучением, измерения спектров КРС и удельной проводимости выполнены на оборудовании Центра коллективного пользования физического факультета МГУ имени М.В. Ломоносова. Для исследования структурных свойств модифицированной поверхности $a$-Si:H методом РЭМ использовалось оборудование Учебно-методического центра литографии и микроскопии МГУ им. М.В. Ломоносова. Работа выполнена при финансовой поддержке Российского фонда фундаментальных исследований (грант № 17-5204062 Бел_мол_а). ), а также Белорусского республиканского фонда фундаментальных исследований (грант № Ф17PM-079). 


\section{Список литературы}

[1] Amasev D.V., Khenkin M.V., Drevinskas R., Kazansky P., Kazanskii A.G. // Tech. Phys. 2017. V. 62. N 6. P. 925.

[2] Емельянов А.В., Казанский А.Г., Кашкаров П.К., Коньков О.И., Теруков Е.И., Фори П.А., Хенкин М.В., Кукин A.B., Beresna M., Kazansky P. // ФТП. 2012. Т. 46. № 6. C. 769; Emelyanov A.V., Kazanskii A.G., Kashkarov P.K., Konkov O.I., Terukov E.I., Forsh P.A., Khenkin M.V., Kukin A.V., Beresna M., Kazansky P. // Semiconductors. 2012. V. 46. N 6. P. 769.

[3] Rybalko P.D., Khenkin M.V., Forsh P.A., Drevinskas R., Matsukatova A.N., Kazansky P., Kazanskii A.G. // J. NanoElectron. Phys. 2016. V. 8. Art. 03038.

[4] Khenkin M., Kazanskii A., Emelyanov A., Forsh P., Beresna M., Gecevicius M., Kazansky P. // Can. J. Phys. 2014. V. 92. P. 883.

[5] Emelyanov A.V, Khenkin M.V., Kazanskii A.G., Forsh P.A., Kashkarov P.K., Gecevicius M., Beresna M., Kazansky P.G. // Thin Solid Films. 2014. V. 556. P. 410.

[6] Wang H., Kongsuwan P., Satoh G., Yao Y.L. // Int. J. Adv. Manuf. Technol. 2013. V. 65. P. 1691.

[7] Wang H., Kongsuwan P., Satoh G., Yao Y.L. // J. Manuf. Sci. Eng. 2012. V. 134. N 3. Art. 031006.

[8] Rudenko A., Colombier J.-P., Höhm S., Rosenfeld A., Krüger J., Bonse J., Itina T.E. // Sci. Rep. 2017. V. 7. N 1. Art. 12306.

[9] Puerto D., Garcia-Lechuga M., Hernandez-Rueda J., GarciaLeis A., Sanchez-Cortes S., Solis J., Siegel J. // Nanotechnology. 2016. V. 27. Art. 265602.

[10] Talbi A., Kaya-Boussougou S., Sauldubois A., Stolz A., Boulmer-Leborgne C., Semmar N. // Appl. Phys. A. 2017. V. 123. P. 463.

[11] Drevinskas R., Beresna M., Gecevičius M., Khenkin M., Kazanskii A.G., Matulaitiene I., Niaura G., Konkov O.I., Terukov E.I., Svirko Y.P. et al. // Appl. Phys. Lett. 2015. V. 106. Art. 171106.

[12] Марииновский Г.А., Шандыбина Г.Д., Дементьева Ю.С., Дюкин Р.В., Заботнов С.В., Головань Л.А., Кашкаров П.К. // ФТП. 2009. Т. 43. № 10. С. 1339; Martsinovsky G.A., Shandybina G.D., Dementieva Yu.S., Dukin R.V., Zabotnov S.V., Golovan L.A., Kashkarov P.K. // Semiconductors. 2009. V. 43. N 10. P. 1298.

[13] Yariv A., Yeh P. Optical Waves in Crystals. NY:: Wiley, 1984. $589 \mathrm{p}$.

[14] Soleymanzadeh B., Beyer W., Luekermann F., Differt D., Pfeiffer W., Stiebig H. // Energy Procedia. 2014. V. 60. P. 90.

[15] Denisova K.N., Fantina N.P., Ilin A.S., Martyshov M.N., Vorontsov A.S. // Biosci., Biotech. Res. Asia. 2016. V. 13. N 4. P. 2359.

[16] Марциновский Г.А., Шандыбина Г.Д., Смирнов Д.С., Заботнов С.В., Головань Л.А., Тимошенко В.Ю., Кашкаров П.К. // ОПт. и спектр. 2008. Т. 105. № 1. С. 55; Martsinovsky G.A., Shandybina G.D., Smirnov D.S., Zabotnov S.V., Golovan L.A., Timoshenko V.Yu., Kashkarov P.K. // Opt. Spectrosc. 2008. V. 105. N 1. P. 55.

[17] Varlamova O., Bounhalli M., Reif J. // Appl. Surf. Sci. 2013. V. 278. P. 62.

[18] Макин В.С., Пестов Ю.И., Макин Р.С. // Опт. и спектр. 2017. T. 123, № 2. C. 264; Makin V.S., Pestov Y.I., Makin R.S. // Opt. Spectrosc. 2017. V. 123 N 2. P. 289.
[19] Danilov P.A., Ionin A.A., Kudryashov S.I., Makarov S.V., Rudenko A.A., Saltuganov P.N., Seleznev L.V., Yurovskikh V.I., Zayarny D.A., Apostolova T. // J. Exp. Theor. Phys. 2015. V. 120. N 6. P. 946.

[20] Kaneko T., Wagashi M., Onisawa K., Minemura T. // Appl. Phys. Lett. 1994. V. 64. P. 1865.

[21] Gogoi P., Dixit P.N., Agarwal P. // Sol. Energy Mater. Solar Cells. 2007. V. 91. P. 1253.

[22] Zhang L., Gao J.H., Xiao J.Q., Wen L.S., Gong J., Sun C. // Appl. Surf. Sci. 2012. V. 258. P. 3221.

[23] Elarbi N., Jemaï R., Outzourhit A., Khirouni K. // Appl. Phys. A. 2016. V. 122. Art. 566.

[24] Голубев В.Г., Давыдов В.Ю., Медведев А.В., Певцов А.Б., Феоктистов Н.А. // ФТТ. 1997. Т. 39. С. 1348.

[25] Zi J., Buscher H., Falter C., Ludwig W., Zhang K., Xie X. // Appl. Phys. Lett. 1996. V. 69. P. 200.

[26] Viera G., Huet S., Boufendi L. // J. Appl. Phys. 2001. V. 90. P. 4175.

[27] Иго А.В. // Опт. и спектр. 2016. Т. 120, № 4. С. 556; Igo A.V. // Opt. Spectrosc. 2016. V. 120 N 4. P. 529.

[28] Bonse J., Brzezinka K.-W., Meixner A.J. // Appl. Surf. Sci. 2004. V. 221. P. 215.

[29] Chavoshi S.Z., Gallo S.C., Dong H., Luo X. // Mater. Sci. Eng. A. 2017. V. 684. P. 385.

[30] Reif J., Costache F., Kouteva-Arguirova S. // Proc. SPIE. 2004. V. 5448. N 2. P. 756.

[31] Costache F., Kouteva-Arguirova S., Reif J. // Appl. Phys. A. 2004. V. 79. P. 1429.

[32] Costache F., Kouteva-Arguirova S., Reif J. // Solid State Phenomena. 2004. V. 95. P. 635.

[33] Smith M.J., Lin Y.-T., Sher M.-J., Winkler M.T., Mazur E., Gradečak S. // J. Appl. Phys. 2011. V. 110. N 5. Art. 053524.

[34] Smith M.J., Sher M.-J., Frant B., Lin Y.-T., Mazur E., Gradečak S. // J. Appl. Phys. 2012. V. 112. N 8. Art. 083518.

[35] Ю П., Кардона М. Основы физики полупроводников. М.: Физматлит, 2002. 560 с.; Yu P., Cardona M. Fundamentals of Semiconductors. Berlin: Springer-Verlag, 2010. 775 p.

[36] Loudon R. // Advances in Physics. 1964. V. 13. N 52. P. 423.

[37] Ефремов М.Д., Болотов В.В., Володин В.А., Кочубей С.А., Кретинин А.В. // ФТП. 2002. Т. 36. № 1. С. 109; Efremov M.D., Bolotov V.V., Volodin V.A., Kochubey S.A., Kretinin A.V. // Semiconductors. 2002. V. 36. N 1. P. 109.

[38] Kuzmin P.G., Shafeev G.A., Bukin V.V., Garnov S.V., Farcau C., Carles R., Watot-Fontrose B., Guieu V., Viau G. // J. Phys. Chem. C. 2010. V. 114. P. 15266. 